\title{
The Potential Influence of Plant Polyphenols on the Aging Process
}

\section{E. Paul Cherniack}

The Geriatrics Institute, University of Miami Miller School of Medicine, Division of Geriatrics and Gerontology, and the Geriatrics and Extended Care Service and Geriatric Research Education, and Clinical Center (GRECC) of the Miami Veterans Affairs Medical Center, Miami, FL, USA

\section{Keywords}

Plant · Polyphenol · Aging · Lifespan

\section{Summary}

Cellular senescence is characterized by cellular hypertrophy: cell growth in the absence of cell division. The genes that regulate this process can be activated or inactivated by numerous plant polyphenols such as resveratrol, quercetin, butein, fistein, piceatannol, curcumin. Many of these substances have been shown to lengthen the lifespan of invertebrates. Many of these compounds have other potential beneficial effects on lifespan as antiatherogenic or antineoplastic agents. Challenges to human testing of such substances on lifespan include determination of dosage, low bioavailability, time and resources necessary to conduct tests, and understanding which formulation of substances to use.

\section{Introduction}

Genetic studies have identified mutations that extend lifespan in certain invertebrates [1]. In the yeast Saccharomyces cerevisiae, deletion of the nutrient-sensing gene TOR (target of rapamycin; an antibiotic) or Sch 9 (a gene in the TOR pathway), and in the roundworm Caenorhabditis elegans mutations of the TOR pathway either downstream DAF-15 or upstream (DAF-2 and DAF-16) increase lifespan [1]. Recent studies have determined that the expression of genes involved in cellular senescence can be modified by plant polyphenols, suggesting that such substances and, potentially, the plants they

\author{
Schlüsselwörter \\ Pflanze · Polyphenol · Alterung · Lebensspanne
}

\section{Zusammenfassung}

Zelluläre Seneszenz ist durch zelluläre Hypertrophie charakterisiert: Zellwachstum in Abwesenheit von Zellteilung. Die Gene, die diesen Prozess bestimmen, können von zahlreichen pflanzlichen Polyphenolen wie Resveratrol, Quercetin, Butein, Fistein, Piceatannol, Curcumin aktiviert oder inaktiviert werden. Es hat sich gezeigt, dass viele dieser Substanzen die Lebensdauer von Wirbellosen verlängern. Etliche dieser Verbindungen haben andere potenziell positive Auswirkungen auf die Lebensspanne als antiatherogene oder antineoplastische Mittel. Erschwernisse für die Prüfung, ob diese Stoffe eine Auswirkung auf die menschliche Lebensdauer haben, beinhalten Bestimmung der Dosis, niedrige Bioverfügbarkeit, erforderliche Zeit und Ressourcen, um Tests durchzuführen, und Kenntnis der zu verwendenden Formulierung.

are derived from may give important clues to how the aging of organisms occurs, and how the process of aging might be slowed or reversed. This manuscript is an unsystematic review obtained by entering search terms such as 'polyphenol' and 'lifespan' into the Medline database.

\section{The Aging Process}

In order to understand these developments, it is necessary to review our current understanding of the aging process. A complete review of this complex topic is beyond the scope of

\section{KARGER}

Fax +497614520714

Information@Karger.de

www.karger.com (c) 2010 S. Karger GmbH, Freiburg

Accessible online at:

www.karger.com/fok
Evan Paul Cherniack, MD

Room 1D200, Miami VA Medical Cente

1201 NW 16 St

Miami FL, 33125, USA

Tel. +1 3055757101, Fax 3055754218

evan.cherniack@va.gov 


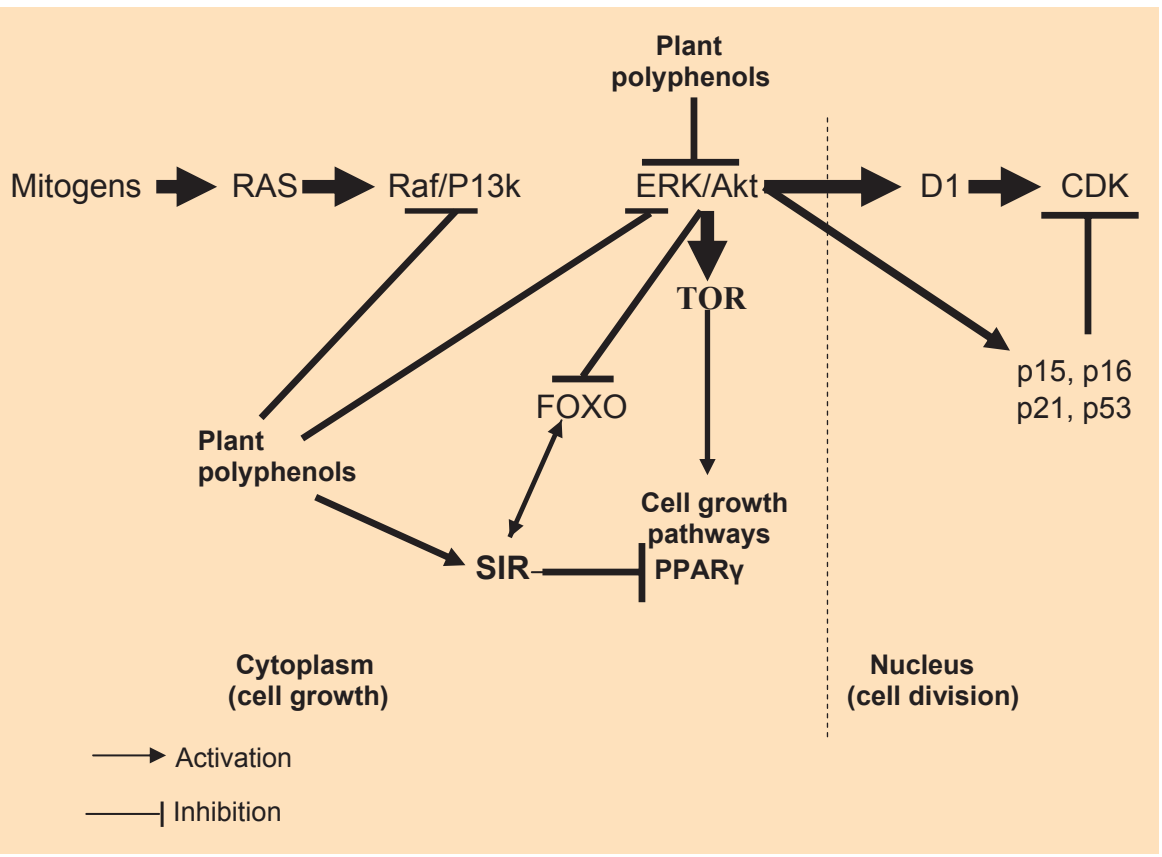

Fig. 1. Signal activation pathways involved in senescence (adapted from Blagosklonny) [1, 23].

this manuscript, but genes that regulate glucose and lipid metabolism, mitochondrial and telomere maintenance, processing of reactive oxygen species, DNA repair, epigenetic alterations in chromatin and histones, and preservation of stem cells may all be involved [2].

At the cellular level, the process of aging is characterized by the activation of certain genes involved in cell growth that regulate glucose and lipid metabolism, resulting in cellular hypertrophy. Hypertrophy is the result of excess stimulation of cells through signaling pathways for cell growth with concomitant blockade of pathways that signal cells to undergo division [1] (fig. 1). These hyperfunctioning cells have increased amounts of mitogens, which include growth factors such as epidermal growth factor (EGF), which stimulate the cytoplasmic genes PI3-K, Akt, Ras, and Raf, and both the PI-3K/Akt and Ras/Raf/ERK gene activation pathways. Genetic modification of $C$. elegans increases the expression of Akt, which increases its lifespan. Akt activation also promotes the renewal of embryonic stem cells in mice [3]. These genes in turn, result in the activation of TOR [1]. TOR acts in response to nutrient levels, growth factors and energy levels within the cell to regulate cell growth [1]. Activation of TOR induces cell growth and insulin resistance, and inhibits apoptosis [1]. Stimulation of a gene downstream of TOR, peroxisome proliferator-activated receptor-gamma (PPAR- $\gamma$ ), will increase the enzyme telomerase, whose absence has been implicated in the process of cell senescence $[4,5]$. TOR also suppresses lysosomal self digestion (autophagy) that is also characteristic of cellular aging $[1,6]$. The result of impaired autophagy can be mitochondrial dysfunction and accumulation of certain proteins such as lipofuscin that can damage the cell [6].
Mitogens also induce the cell to progress along the cell cycle to division via the nuclear genes cyclin and CDK1 (cyclin-dependent kinase-1) through the CDK gene pathway [1]. However, excessive stimulation will arrest the cell cycle by activating the inhibitory p15, p16, p53, and p21 genes. Senescent cells have elevated expression of both cyclin and p21 [1].

The characteristic phenotype of senescent cells and organs in diseases that are more prevalent at older ages is hypertrophic [1]. For example, in atherosclerosis, a characteristic feature is the growth of cardiac and endothelial myocytes, which increase in contractility. Another example is osteoporosis, characterized by hyperfunctioning osteoclasts that break down and remodel large amounts of bone [1]. While the deletion of TOR in developing mammals is lethal, inhibition later in the organism's life, or inhibition of the genes in the TOR pathway, as previously mentioned, prolongs lifespan [1]. Numerous plant polyphenols may act on the TOR pathway and potentially influence the process of cellular senescence. Polyphenols have been more extensively examined for their effect on TOR-pathway genes $[1,7,8]$. Furthermore, genes in the TOR pathway are involved in the pathology of diseases prevalent in old age including osteoporosis, Alzheimer's disease and the metabolic syndrome [1].

The most well-studied of these substances are resveratrol and quercetin [9]. They are present in numerous plants including grapes, blueberries, cranberries, and tomatoes.

\section{Resveratrol: Effect on Lifespan}

Resveratrol, which is found in more than 70 different species of plants, has thus far been the most intensely scrutinized 
plant polyphenol for its effect on cellular senescence $[9,10]$. While resveratrol is often associated with red wine, commercially it is prepared from a less expensive source, Polygonum cuspidatum (Japanese knotweed). The almond-tasting knotweed shoots can be eaten, although the plant may also contain carcinogenic tannins [11]. Polygonum is also dried and used in Chinese and Japanese medicine, known as hu zhang, for multiple uses, including as a laxative $[11,12]$.

Use of resveratrol has increased lifespan in several, but not all species in which it was tested. The lifespan of $S$. cerevisiae, when cultured with $10 \mu \mathrm{M}$ resveratrol was increased by $70 \%$ [13]. The lifespans of C. elegans and the fruit fly Drosophila melanogaster lengthened by 20 and $29 \%$, respectively, when grown with $100 \mu \mathrm{M}$ of resveratrol [14]. The 2-month life span of a fish, Nothobranchius furzeri, fed $120 \mu \mathrm{g}$ resveratrol/g food increased by $50 \%[15,16]$. Mice, who were fed a lifespanreducing high-fat diet, lived as long as mice who consumed a normal diet when supplemented with $22.4 \mathrm{mg}$ resveratrol $/ \mathrm{kg}$ body weight [17].

An increase in lifespan was not seen in mice who consumed resveratrol with a normal diet [17]. Human fibroblasts cultured in resveratrol also failed to live longer [18].

\section{Mechanisms of Action of Resveratrol's Effect on Lifespan}

The mechanism by which resveratrol induces lifespan extension remains controversial. Plant polyphenols, such as resveratrol, downregulate cellular growth genes stimulated by mitogens, such as P13k and AKT, which are part of the TOR pathway (fig. 1) [19]. Resveratrol is believed to activate genes known as sirtuins (Sir [invertebrates] or Sirt [vertebrates]), thought to be responsible for the life-extending effects of calorie restriction [20, 21]. Sirtuins cause an important posttranslational change in proteins in histones (deacetylation), which affect protein stability and conformation [22]. Sirtuins promote gene stability after DNA breakage [7-9]. (Inhibition of TOR also increases the activity of at least one sirtuin, but resveratrol may activate sirtuins independently of TOR [23].)

However, the relationship between resveratrol and sirtuins is complex. Some studies in yeast have suggested that resveratrol does not activate the yeast sirtuin gene, Sir2 [14, 15]. Vertebrates have many more sirtuin genes whose function is complex. In mice, resveratrol did not activate the mammalian counterpart of invertebrate sirtuin, Sirt1, but did activate a different sirtuin, Sirt5, and several other genes that regulate chromatin assembly and disassembly [24]. Furthermore, resveratrol has multiple genetic targets in the cellular growth and energy-sensing gene pathways [25].

The interaction between resveratrol and sirtuins may in part explain another influence of resveratrol on aging, its ability to reverse the reduced mitochondrial biogenesis that occurs in senescent cells [26, 27]. The sirtuin-mediated stimula- tion of AMP-medicated kinase (AMPK) by reseveratrol is important to mitochondrial biogenesis [27]. AMPK is also an energy regulatory molecule that is involved in insulin, glucose, and fatty acid metabolism [27]. The effect of resveratrol on lipid and glucose metabolism might potentially increase the lifespan of higher organisms through its systemic effects on lipid and glucose metabolism. Resveratrol prevents incorporation of lipids in vitro into animal and human adipocytes and inhibiting adipocyte maturation [28, 29]. Sirtuin activation inhibits the PPAR- $\gamma$ gene and ribosomal DNA transcription in adipocytes, resulting in lipolysis [7-9, 30, 31]. Sirtuin stimulation regulates adipocyte differentiation through the acetylation of the FOXO1 gene [32]. Transgenetic mice that overexpress Sirt1 and Sirt 6 are protected from higher lipid levels and adipocyte-produced pro-inflammatory cytokines [33, 34]. In mice in vivo, resveratrol lowers free fatty acids levels and insulin growth factor (IGF-1) levels, elevates levels of AMPK, and increases number of mitochondria which sense energy levels, which raises insulin sensitivity [35].

Resveratrol might also increase lifespan in higher organisms through an anti-inflammatory effect that could prevent disease-inducing cellular injury. In vitro, resveratrol inhibited inflammation caused by LDL oxidation, angiotensin-II release, and platelet aggregation. Resveratrol also suppressed inflammatory cytokines including $\mathrm{NF}-\kappa \mathrm{B}$, and endothelial intercellular cell adhesion molecule (ICAM-1). Resveratrol promoted nitric oxide release, causing vasodilation of human arteries [35, 36]. Resveratrol lessened ischemic injury in reperfused rat hearts [35]. Resveratrol raised the aerobic capacity and endurance of mice while running through enhanced muscle mitochondrial function [26]. In a recent human trial of 8 healthy men who took $100 \mathrm{mg}$ resveratrol daily for 6 weeks, peripheral blood monocytes demonstrated a reduced expression of the pro-inflammatory genes NF- $\kappa \mathrm{B}$, JNK-1, IKKb, and SOCS-3 and enhanced levels of insulin substrate-1, which increases insulin sensitization [37]. In another investigation, 44 pre- and postmenopausal women who consumed a mixture of $36 \mathrm{~g}$ grape powder daily for 4 weeks that included $7 \mu \mathrm{mol} / \mathrm{kg}$ resveratrol and $0.77 \mathrm{~g} / \mathrm{kg}$ quercetin had significantly lower triglyceride ( $15 \%$ in pre- and $6 \%$ in postmenopausal women) and LDL cholesterol levels (10\% in premenopausal women) [38].

Since it is found in high concentrations in certain grapes and red wines, resveratrol has been postulated to be responsible for the 'French paradox' (i.e., the inverse relationship of the incidence of heart disease in France to wine consumption unrelated to dietary fat ) [39-41]. Wine consumption has been associated with higher HDL cholesterol levels, inhibition of platelet aggregation, higher levels of nitric oxide (NO), an important vasodilator, increased serum antioxidant levels, and lower levels of pro-inflammatory cytokines [39]. Nitric oxide can protect the heart from the repeated stress of ischemia and reperfusion 'preconditioning' [39, 40]. Resveratrol improves vascular blood flow by cytokine-NO-dependent mechanism in animal models of ischemia [39]. 
However, consumption of other forms of alcohol, and white wine, or seasonings used in French cuisine might also confer such benefits [39, 42-44]. Other confounding factors, such as variations in amount of resveratrol in different wines, and the rapid metabolism of resveratrol in man, are complicating factors in assessing such an epidemiological connection [35].

Resveratrol may confer other health benefits to higher organisms that may increase lifespan, including the possible prevention or treatment of cancer, neurodegenerative disease, and infection $[17,18]$. Resveratrol activates cell cycle modifying genes, such as cyclin, p21, and tumor suppressor genes, including p53, and induces other genes that result in apoptosis, while inhibiting other genes that cause proliferation of neoplastic cells $[10,19]$. The anti-inflammatory effects of resveratrol suppress neoplasm growth (and metastasis through its effect on angiogenesis) [10]. Nitric oxide, which can be stimulated by resveratrol, reduces oxidative stress and is neuroprotective in vitro [45, 46]. Resveratrol stimulates natural killer cells and macrophages and improves survival from bacterial pneumonia in rats in vivo [47]. Resveratrol inhibited the growth of tumors and metastasis in mouse tumor xenografts [10]. In animal tumor models, resveratrol causes a reversible retardation of the S-phase and DNA synthesis, which might potentially give additional time for DNA repair mechanisms to act [48]. However, resveratrol may also promote apoptosis in normal chondrocytes, lymphocytes, and endothelial cells in vitro [49].

\section{Quercetin}

Another polyphenol, quercetin, found in many plants including grapes, blueberries, cherries, onions, and broccoli, may have anti-aging properties [50]. Quercetin inhibits the metabolism of resveratrol, potentiating its effect [49]. Quercetin increased the lifespan of the nematode Caenorhabditis elegans grown in $200 \mu \mathrm{M}$ by approximately $20 \%$ [50, 51]. A combination of quercetin and reseveratrol inhibited the maturation of mouse adipocytes and promoted their apoptosis in vitro [52]. Quercetin and its analogues stimulated the apoptosis of human cancer cells in vitro through the activation of ERK or inhibition of Ras genes (fig. 1) [7, 53, 54].

Quercetin, like resveratrol and other polyphenols, has antioxidant properties [55-58]. Quercetin reduced lipid peroxidation products and increased levels of the antioxidant glutathione in the brains of mice [59]. Rat lung cells grown in quercetin are buffeted against hydrogen peroxide-induced injury [60]. However, quercetin also lowered glutathione levels [60]. Furthermore, while oxidant-induced damage has been theorized to cause genetic damage, inducing cellular senescence $[6,45]$, it is also now recognized that oxidizing free-radical molecules may also serve useful purpose as intracellular signal messengers, are antimicrobial, and metabolize potentially toxic substances $[6,55]$. In addition, humans appear to die from conditions involving cellular hypertrophy rather than excessive molecular oxidation, and clinical trials of antioxidants have failed to demonstrate an effect on mortality [6].

In addition to a potential antioxidant effect, quercetin has anti-inflammatory properties. Quercetin reduced levels of the pro-inflammatory cytokine tumor necrosis factor- $\alpha$ (TNF- $\alpha$ ) in 7 healthy individuals (ages 20-40) who drank $97 \mathrm{~g}$ daily of blueberry-apple juice mixture (97 mg quercetin) while on a quercetin-free diet for 1 month [61]. TNF production was also lower in an in vitro blood preparation from human subjects [61].

\section{Other Plant Polyphenols}

Other plant polyphenols, while not as potent sirtuin activators as resveratrol [13], do activate other genes that potentially make them useful in retarding cellular aging. Two of the compounds, fistein and butein, caused a $33 \%$ and $5 \%$ lifespan lengthening in the yeast Saccharomyces cerevisiae cultured at a concentration of $10 \mu \mathrm{M}$ of each [13].

Since some of the genes these polyphenols are believed to activate in prolonging survival might also regulate the lifespan of neoplastic cells, these substances are also being studied for their potential to treat cancer. Butein inhibited the cell growth gene ERK $1 / 2$ activated by mitogens in bladder cancer cells [62]. Piceatannol arrested colon cancer cells in the S-phase, and downregulated cyclin D1, B1 and cdk4 [63]. Yet another polyphenol, fisetin, downregulated the expression of the mitogen-induced genes ERK, MAPK, and p38 in the human leukemia (HL60) cell line [64].

Another polyphenol that might retard cellular senescence is curcumin, which is derived from 31 species of Curcuma plants, including Curcuma longa, the rhizome of which provides the spice turmeric $[65,66]$. Curcumin inhibits the TOR activation pathway $[8,65]$. As is the case with other polyphenols, the action of curcumin on TOR pathway genes has implications for the treatment of cancer as well as the reversal of aging. In human prostate cancer cells, curcumin suppressed the activating phosphorylation of the Akt gene and other genes downstream in the TOR pathway [65]. Curcumin also caused cell cycle arrest in colon cancer cells through activation of the p53 pathway, and inhibited the P13K, Akt, Cox-2, and cyclin D1 genes [67].

\section{Challenges in Cellular Senescence Research with Phytochemicals}

While the list of phytochemicals that may retard cellular senescence is growing, few human studies on these substances have been performed. One major impediment is the length of the human lifespan. If a putative agent to retard the aging 
process was explored in a population of individuals, it would take decades to conduct and ascertain the results of such a trial. It would be a daunting task to find individuals or entities with the time and resources necessary to undertake such a venture.

Therefore, subject selection remains a challenge. Resveratrol, the most extensively studied polyphenol, increases lifespan in yeast, roundworms, and fish, but does not lengthen lifespan in mice (unless overfed), the closest organism to humans examined, but with a lifespan short enough to study for a practical length of time. The explanation for the lack of effect needs explanation. One possibility is that resveratrol acts differently in mammals and higher organisms due to the greater complexity of their sirtuins. Another is that the mice were too old (middle aged, i.e., 1-year old, out of a typical lifespan of 2 in the laboratory) when the polyphenol was started [68]. In addition, since an important effect of resveratrol is its effect on lipid and glucose metabolism, and cardiovascular disorders are not a common cause of death in mice, lifespan was not extended [25]. In humans, however, cardiovascular diseases are an important cause of death.

Given the potential influence of other dietary substances, a significant related controversy that might impact subject selection is whether plant polyphenols, such as resveratrol, act as analogues to a known method of lifespan extension in many organisms: calorie restriction. Calorie restriction augments the lifespan of monkeys, mice, and invertebrates, but its effect on humans remains uncertain [25]. Furthermore, many individuals may be unwilling to reduce their caloric intake. The effect of dietary restriction is hypothesized to be mediated through the energy-sensing mechanism of the sirtuin gene or a co-substrate [25]. While the relationship between the action of resveratrol and calorie restriction is a complex topic (see Baur et al [25] for a more complete discussion), many similarities exist in their mechanisms and effects [25]. Ascertaining such effects of polyphenols is complicated by uncertainty over dosing of these substances due to persisting controversy about their bioavailability, in vivo. Grape polyphenols and curcumin are poorly absorbed by humans and readily metabolized [69-72]. Several investigations suggest they may not reach plasma concentrations in humans that induce anti-aging effects [69-71]. While the half life of the trans-isomer of resveratrol is between $2-5 \mathrm{~h}$, urine metabolites can be found up to almost a month later, and the bioavailability of the cis-isomer has not been well-studied [73]. There have been significant variations in doses or resveratrol employed in both in vitro (ca. 32-100 nM) and in vivo studies
(100 ng - $1.5 \mathrm{~g} / \mathrm{kg}$ body weight) [74]. Quercetin administration can raise human serum concentrations into anti-inflammatory nanomolar levels, although micromolar concentrations were employed to increase lifespan in C. elegans [50, 61]. Published human bioavailability studies of fistein, butein, and piceatannol have not appeared yet.

In healthy volunteers, a single oral dose of $650 \mathrm{mg}$ of a capsule of $>95 \%$ curcuminoids resulted in undetectable serum levels up to $6 \mathrm{~h}$ later, and oral doses up to $12 \mathrm{gm}$ in other human trials have yielded serum levels in only nanogram concentrations $[71,75,76]$. New formulations of curcumin, such as nanocurcumin, in which the compound is encapsulated in polymeric nanoparticles, curcumin liposomes, and phospholipid complexes, have been developed to increase aqueous solubility to increase absorption [77, 78]. In vivo trials of several formulations successfully increased in vivo animal and human absorption [75, 79-81].

Although it is possible that the metabolites of polyphenols are also active, neither their complete identities nor potential activities are well known [73, 82]. Quercetin metabolites can inhibit enzyme activity, cell growth and proliferation in vitro [41]. Resveratrol can be metabolized into piceatannol [83]. In vitro, both can interact to alter lipid characteristics in model membranes [83].

In nature, these polyphenols and their metabolites are not present as isolated substances, but exist in a plant together with a myriad of other phytochemicals, which may also confer health benefits [84], and the optimal benefit may be from naturally-occuring or other dietary combinations. In grapes, resveratrol and quercetin are found together. In one investigation, an extract of multiple blueberry polyphenols extended the lifespan of $C$. elegans [85]. The effects of phytochemicals may be enhanced after metabolism by the organism [86]. New synergistic combinations of polyphenols may be required to maximize anti-aging effects.

\section{Conclusion}

Research in invertebrates and fish has identified one or more plant polyphenols that have prolonged lifespan. However, in higher organisms, the longer lifespan and greater complexity of the cellular metabolic pathways have precluded efforts to demonstrate a lifespan lengthening effect. Newer formulations of polyphenols, possibly compounds, and innovations in research design may allow the opportunity to show lifespanenhancing effects in higher organisms as well. 


\section{References}

1 Blagosklonny MV: Aging and immortality: quasiprogrammed senescence and its pharmacologic inhibition. Cell Cycle 2006;5(18):2087-102.

2 Marques FZ, Markus MA, Morris BJ: The molecular basis of longevity, and clinical implications. Maturitas 2010;65(2):87-91.

3 Miura T, Mattson MP, Rao MS: Cellular lifespan and senescence signaling in embryonic stem cells. Aging Cell 2004;3(6):333-43.

4 Makino N, Maeda T, Oyama J, Higuchi Y, Mimori $\mathrm{K}$ : Improving insulin sensitivity via activation of PPAR-gamma increases telomerase activity in the heart of OLETF rats. Am J Physiol Heart Circ Physiol 2009;297(6):H2188-95.

5 Hornsby PJ: Telomerase and the aging process Exp Gerontol 2007;42(7):575-81.

6 Blagosklonny MV: Aging: ROS or TOR. Cell Cycle 2008;7(21):3344-54.

7 Nguyen TT, Tran E, Nguyen TH, Do PT, Huynh TH, Huynh H: The role of activated MEK-ERK pathway in quercetin-induced growth inhibition and apoptosis in A549 lung cancer cells. Carcinogenesis 2004;25(5):647-59.

$\checkmark 8$ Beevers CS, Chen L, Liu L, Luo Y, Webster NJ, Huang S: Curcumin disrupts the Mammalian target of rapamycin-raptor complex. Cancer Res 2009;69 (3):1000-8.

$\checkmark 9$ Knutson MD, Leeuwenburgh C: Resveratrol and novel potent activators of SIRT1: effects on aging and age-related diseases. Nutr Rev 2008;66 (10):591-6.

10 Kundu JK, Surh YJ: Cancer chemopreventive and therapeutic potential of resveratrol: mechanistic perspectives. Cancer Lett 2008;269(2):243-61.

11 Ohio Agricultural Research and Development Center (OARDC), Ohio State University: Japanese knotweed. The Ohio perennial and biennial weed guide. www.oardc.ohio-state.edu/weedguide/ singlerecord.asp? $\mathrm{id}=230$.

12 Gawne G: Resveratrol News. www.resveratrolnews.com/page 50.htm.

13 Howitz KT, Bitterman KJ, Cohen HY, Lamming DW, Lavu S, Wood JG et al: Small molecule activators of sirtuins extend Saccharomyces cerevisiae lifespan. Nature 2003;425(6954):191-6.

14 Wood JG, Rogina B, Lavu S, Howitz K, Helfand SL, Tatar M et al: Sirtuin activators mimic caloric restriction and delay ageing in metazoans. Nature 2004;430(7000):686-9.

15 Valenzano DR, Cellerino A: Resveratrol and the pharmacology of aging: a new vertebrate model to validate an old molecule. Cell Cycle 2006;5(10): 1027-32.

16 Valenzano DR, Terzibasi E, Genade T, Cattaneo A, Domenici L, Cellerino A: Resveratrol prolongs lifespan and retards the onset of age-related markers in a short-lived vertebrate. Curr Biol 2006;16 (3):296-300.

17 Baur JA, Pearson KJ, Price NL, Jamieson HA, Lerin C, Kalra A et al: Resveratrol improves health and survival of mice on a high-calorie diet. Nature 2006;444(7117):337-42.

18 Stefani M, Markus MA, Lin RC, Pinese M, Dawes IW, Morris BJ: The effect of resveratrol on a cell model of human aging. Ann N Y Acad Sci 2007; 1114:407-18.

19 Shakibaei M, Harikumar KB, Aggarwal BB: Resveratrol addiction: to die or not to die. Mol Nutr Food Res 2009;53(1):115-28.

20 Longo VD: Linking sirtuins, IGF-I signaling, and starvation. Exp Gerontol 2009;44(1-2):70-4.
Donmez G, Guarente L: Aging and disease: con nections to sirtuins. Aging Cell 2010;9:285-90.

22 Trapp J, Jung M: The role of NAD+ dependent histone deacetylases (sirtuins) in ageing. Curr Drug Targets 2006;7(11):1553-60.

23 Blagosklonny MV: An anti-aging drug today: from senescence-promoting genes to anti-aging pill. Drug Discov Today 2007;12(5-6):218-24.

24 Barger JL, Kayo T, Vann JM, Arias EB, Wang J, Hacker TA et al: A low dose of dietary resveratrol partially mimics caloric restriction and retards aging parameters in mice. PLoS ONE 2008; 3(6):e2264.

25 Baur JA: Resveratrol, sirtuins, and the promise of a DR mimetic. Mech Ageing Dev 2010;131(4): 261-9.

26 Lagouge M, Argmann C, Gerhart-Hines Z, Meziane H, Lerin C, Daussin F et al: Resveratrol improves mitochondrial function and protects against metabolic disease by activating SIRT1 and PGC-1alpha. Cell 2006;127(6):1109-22.

27 Lopez-Lluch G, Irusta PM, Navas P, de Cabo R: Mitochondrial biogenesis and healthy aging. Exp Gerontol 2008;43(9):813-9.

28 Rayalam S, Della-Fera MA, Baile CA: Phytochemicals and regulation of the adipocyte life cycle. J Nutr Biochem 2008;19(11):717-26.

29 Fischer-Posovszky P, Unterkircher T, Fulda S, Debatin KM, Wabitsch M: Sirt1 Is Involved in Resveratrol-Stimulated Changes in Human Adipocytes. The Endocrine Society's Annual Meeting. San Francisco, CA, June 15-18, 2008

30 Picard F, Kurtev M, Chung N, Topark-Ngarm A, Senawong T, Machado De Oliveira R et al: Sirt1 promotes fat mobilization in white adipocytes by repressing PPAR-gamma. Nature 2004;429(6993): 771-6.

31 Szkudelska K, Nogowski L, Szkudelski T: Resveratrol, a naturally occurring diphenolic compound, affects lipogenesis, lipolysis and the antilipolytic action of insulin in isolated rat adipocytes. J Steroid Biochem Mol Biol 2009;113(1-2):17-24.

32 Jing E, Gesta S, Kahn CR: SIRT2 regulates adipocyte differentiation through FoxO1 acetylation/ deacetylation. Cell Metab 2007;6(2):105-14.

33 Domnez G, Guarente L: Aging and disease: connections to sirtuins. Aging Cell 2010;9:285-90.

34 Kanfi Y, Peshti V, Gil R, Naiman S, Nahum L, Kronfeld-Schor N, Cohen HY: SIRT6 protects against pathological damage caused by diet-induced obesity. Aging Cell 2010;9:162-73.

35 Opie LH, Lecour S: The red wine hypothesis: from concepts to protective signalling molecules. Eur Heart J 2007;28(14):1683-93.

36 Cacciapuoti F: Opposite effects of metabolic syndrome and calorie restriction on thrombotic disease: head and tail of same coin-resveratrol's role. Metab Syndr Relat Disord 2009;7(5):397-400.

37 Dandona P, Mohanty P, Ghanim H, Marumganti A, Sia C, Abuaysheh S, Rajeswari J: Resveratrol suppresses Pro-Inflammatory Genes Causing Insulin Resistance. The Endocrine Society's 90th Annual Meeting San Francisco, CA, 2008.

38 Zern TL, Wood RJ, Greene C, West KL, Liu Y, Aggarwal D et al: Grape polyphenols exert a cardioprotective effect in pre- and postmenopausal women by lowering plasma lipids and reducing oxidative stress. J Nutr 2005;135(8):1911-7.

39 Vidavalur R, Otani H, Singal PK, Maulik N: Significance of wine and resveratrol in cardiovascular disease: French paradox revisited. Exp Clin Cardiol 2006;11(3):217-25.
40 Lekli I, Ray D, Das DK: Longevity nutrients resveratrol, wines and grapes. Genes Nutr 2010;5(55$60)$.

41 Brown L, Kroon PA, Das DK, Das S, Tosaki A, Chan $\mathrm{V}$ et al: The biological responses to resveratrol and other polyphenols from alcoholic beverages. Alcohol Clin Exp Res 2009;33(9):1513-23.

42 Dudley JI, Lekli I, Mukherjee S, Das M, Bertelli AA, Das DK: Does white wine qualify for French paradox? Comparison of the cardioprotective effects of red and white wines and their constituents: resveratrol, tyrosol, and hydroxytyrosol. J Agric Food Chem 2008;56(20):9362-73.

43 Pinzani P, Petruzzi E, Magnolfi SU, Malentacchi F, De Siena G, Petruzzi I et al: Red or white wine assumption and serum antioxidant capacity. Arch Gerontol Geriatr 2010 Jan 13 [Epub ahead of print].

44 Morre DJ, Morre DM, Shelton TB: Aging-related nicotinamide adenine dinucleotide oxidase response to dietary supplementation: the French paradox revisited. Rejuvenation Res 2010;13(2-3): 159-61.

45 Calabrese V, Maines MD: Antiaging medicine: antioxidants and aging. Antioxid Redox Signal 2006;8(3-4):362-4.

46 Calabrese V, Stella AM, Butterfield DA, Scapagnini G: Redox regulation in neurodegeneration and longevity: role of the heme oxygenase and HSP70 systems in brain stress tolerance. Antioxid Redox Signal 2004;6(5):895-913.

47 Lu CC, Lai HC, Hsieh SC, Chen JK: Resveratrol ameliorates Serratia marcescens-induced acute pneumonia in rats. J Leukoc Biol 2008;83(4): 1028-37.

48 Zhou R, Fukui M, Choi HJ, Zhu BT: Induction of a reversible, non-cytotoxic S-phase delay by resveratrol: implications for a mechanism of lifespan prolongation and cancer protection. Br J Pharmacol 2009;158(2):462-74.

49 Csaki C, Keshishzadeh N, Fischer K, Shakibaei $\mathrm{M}$ : Regulation of inflammation signalling by resveratrol in human chondrocytes in vitro. Biochem Pharmacol 2008;75(3):677-87.

50 Pietsch K, Saul N, Menzel R, Sturzenbaum SR, Steinberg CE: Quercetin mediated lifespan extension in Caenorhabditis elegans is modulated by age- 1 , daf-2, sek-1 and unc- 43 . Biogerontology 2009;10(5):565-78.

51 Saul N, Pietsch K, Menzel R, Steinberg CE: Quercetin-mediated longevity in Caenorhabditis elegans: Is DAF-16 involved? Mech Ageing Dev 2008;129(10):611-3.

52 Yang JY, Della-Fera MA, Rayalam S, Ambati S, Hartzell DL, Park HJ et al: Enhanced inhibition of adipogenesis and induction of apoptosis in 3T3-L1 adipocytes with combinations of resveratrol and quercetin. Life Sci 2008;82(19-20):1032-9.

53 Lin CW, Hou WC, Shen SC, Juan SH, Ko CH, Wang LM et al: Quercetin inhibition of tumor invasion via suppressing PKC delta/ERK/AP-1dependent matrix metalloproteinase- 9 activation in breast carcinoma cells. Carcinogenesis 2008;29(9): 1807-15.

54 Psahoulia FH, Moumtzi S, Roberts ML, Sasazuki T, Shirasawa S, Pintzas A: Quercetin mediates preferential degradation of oncogenic Ras and causes autophagy in Ha-RAS-transformed human colon cells. Carcinogenesis 2007;28(5):1021-31.

55 Boots AW, Haenen GR, Bast A: Health effects of quercetin: from antioxidant to nutraceutical. Eur J Pharmacol 2008;585(2-3):325-37. 
56 Gorelik S, Ligumsky M, Kohen R, Kanner J: The stomach as a 'bioreactor': when red meat meets red wine. J Agric Food Chem 2008;56(13):5002-7.

57 Duthie GG, Gardner PT, Kyle JA: Plant polyphenols: are they the new magic bullet? Proc Nutr Soc 2003;62(3):599-603.

58 Bors W, Saran M: Radical scavenging by flavonoid antioxidants. Free Radic Res Commun 1987;2(4 6):289-94.

59 Singh A, Naidu PS, Kulkarni SK: Reversal of aging and chronic ethanol-induced cognitive dysfunction by quercetin a bioflavonoid. Free Radic Res 2003;37(11):1245-52.

-60 Boots AW, Li H, Schins RP, Duffin R, Heemskerk JW, Bast A et al: The quercetin paradox. Toxicol Appl Pharmacol 2007;222(1):89-96.

61 Boots AW, Wilms LC, Swennen EL, Kleinjans JC, Bast A, Haenen GR: In vitro and ex vivo anti-inflammatory activity of quercetin in healthy volunteers. Nutrition 2008;24(7-8):703-10.

62 Zhang L, Chen W, Li X: A novel anticancer effect of butein: inhibition of invasion through the ERK1/2 and NF-kappa B signaling pathways in bladder cancer cells. FEBS Lett 2008;582(13):1821-8.

63 Wolter F, Clausnitzer A, Akoglu B, Stein J: Piceatannol, a natural analog of resveratrol, inhibits progression through the $\mathrm{S}$ phase of the cell cycle in colorectal cancer cell lines. J Nutr 2002;132(2):298302

-64 de Sousa RR, Queiroz KC, Souza AC, Gurgueira SA, Augusto AC, Miranda MA et al: Phosphoprotein levels, MAPK activities and NFkappaB expression are affected by fisetin. J Enzyme Inhib Med Chem 2007;22(4):439-44.

65 Yu S, Shen G, Khor TO, Kim JH, Kong AN: Curcumin inhibits Akt/mammalian target of rapamycin signaling through protein phosphatase-dependent mechanism. Mol Cancer Ther 2008;7(9):2609-20.

66 Itokawa H, Shi Q, Akiyama T, Morris-Natschke SL, Lee KH: Recent advances in the investigation of curcuminoids. Chin Med 2008;3:11.
Sa G, Das T: Anti cancer effects of curcumin: cycle of life and death. Cell Div 2008;3:14

68 Pearson KJ, Baur JA, Lewis KN, Peshkin L, Price NL, Labinskyy $\mathrm{N}$ et al: Resveratrol delays agerelated deterioration and mimics transcriptional aspects of dietary restriction without extending life span. Cell Metab 2008;8(2):157-68

69 Scalbert A, Williamson, G: Dietary intake and bioavailability of polyphenols. J Nutr 2000;130: 2073S—85S.

70 Bravo L: Polyphenols: chemistry, dietary sources, metabolism, and nutritional significance. Nutr Rev 1998;56(11):317-33.

71 Anand P, Kunnumakkara AB, Newman RA, Aggarwal BB: Bioavailability of curcumin: problems and promises. Mol Pharm 2007;4(6):807-18.

72 Anand P, Thomas SG, Kunnumakkara AB, Sundaram C, Harikumar KB, Sung B et al: Biological activities of curcumin and its analogues (Congeners) made by man and Mother Nature. Biochem Pharmacol 2008;76(11):1590-611.

73 Cottart CH, Nivet-Antoine V, Laguillier-Morizot C, Beaudeux JL: Resveratrol bioavailability and toxicity in humans. Mol Nutr Food Res 2010;54(1): 7-16.

74 Baur JA, Sinclair DA: Therapeutic potential of resveratrol: the in vivo evidence. Nat Rev Drug Discov 2006;5(6):493-506.

75 Gota VS, Maru GB, Soni TG, Gandhi TR, Kochar N, Agarwal MG: Safety and pharmacokinetics of a solid lipid curcumin particle formulation in osteosarcoma patients and healthy volunteers. J Agric Food Chem 2010;58(4):2095-9.

76 Dhillon N, Aggarwal BB, Newman RA, Wolff RA, Kunnumakkara AB, Abbruzzese JL et al: Phase II trial of curcumin in patients with advanced pancreatic cancer. Clin Cancer Res 2008;14(14):4491-9.

77 Bisht S, Feldmann G, Soni S, Ravi R, Karikar C, Maitra A: Polymeric nanoparticle-encapsulated curcumin ('nanocurcumin'): a novel strategy for human cancer therapy. J Nanobiotechnology 2007;5:3.
8 Padhye S, Chavan D, Pandey S, Deshpande J, Swamy KV, Sarkar FH: Perspectives on chemopreventive and therapeutic potential of curcumin analogs in medicinal chemistry. Mini Rev Med Chem 2010;10(5):372-87.

79 Onoue S, Takahashi H, Kawabata Y, Seto Y, Hatanaka J, Timmermann B et al: Formulation design and photochemical studies on nanocrystal solid dispersion of curcumin with improved oral bioavailability. J Pharm Sci 2010;99(4):1871-81.

80 Anand P, Nair HB, Sung B, Kunnumakkara AB Yadav VR, Tekmal RR et al: Design of curcuminloaded PLGA nanoparticles formulation with enhanced cellular uptake, and increased bioactivity in vitro and superior bioavailability in vivo. Biochem Pharmacol 2010;79(3):330-8.

81 Antony B, Merina B, Iyer VS, Judy N, Lennertz K Joyal S: A pilot cross-over study to evaluate human oral bioavailability of bcm-95cg (biocurcumax). a novel bioenhanced preparation of curcumin. Indian J Pharm Sci 2008;70(4):445-9.

$82 \mathrm{Hu} \mathrm{M}$ : Commentary: bioavailability of flavonoids and polyphenols: call to arms. Mol Pharm 2007;4(6):803-6.

83 Wesolowska O, Kuzdzal M, Strancar J, Michalak $\mathrm{K}$ : Interaction of the chemopreventive agent resveratrol and its metabolite, piceatannol, with model membranes. Biochim Biophys Acta 2009;1788 (9):1851-60.

84 Lila MA: From beans to berries and beyond teamwork between plant chemicals for protection of optimal human health. Ann N Y Acad Sci 2007;1114:372-80.

85 Wilson MA, Shukitt-Hale B, Kalt W, Ingram DK, Joseph JA, Wolkow CA: Blueberry polyphenols increase lifespan and thermotolerance in Caenorhabditis elegans. Aging Cell 2006;5(1):59-68.

86 Seeram NP: Berry fruits: compositional elements, biochemical activities, and the impact of their intake on human health, performance, and disease. J Agric Food Chem 2008;56(3):627-9. 